\title{
Response surface optimisation for the extraction of phenolic compounds and antioxidant capacities of underutilised Mangifera pajang Kosterm. peels.
}

\begin{abstract}
The optimum extraction conditions for highest recovery of total phenolics content (TPC) and antioxidant capacities (AC) were analysed for Mangifera pajang peels (MPP), using response surface methodology. The effects of ethanol concentration (X1: 20-80\%), extraction temperature $\left(\mathrm{X} 2: 30-65^{\circ} \mathrm{C}\right)$ and liquid-to-solid ratio $(\mathrm{X} 3: 20-50 \mathrm{~mL} / \mathrm{g})$ on the recovery of total phenolics (Y1) and antioxidant capacity (Y 2) were investigated. A second order polynomial model produced a satisfactory fitting of the experimental data with regard to total phenolic content $(\mathrm{R} 2=0.9966, \mathrm{p}<0.0001)$ and antioxidant capacity $(\mathrm{R} 2=0.9953, \mathrm{p}<0.0001)$. The optimum extraction conditions for TPC were $68 \%, 55^{\circ} \mathrm{C}$ and $32.7 \mathrm{~mL} / \mathrm{g}$, and for AC were $68 \%, 56^{\circ} \mathrm{C}$ and $31.8 \mathrm{~mL} / \mathrm{g}$, respectively. Predicted values for extraction of TPC and AC agreed well with the experimental values. Liquid chromatography-mass spectrometry of the optimally obtained extracts from MPP revealed the major phytochemicals as mangiferin, gallic acid, catechin and epicatechin. () 2011 Elsevier Ltd. All rights reserved.
\end{abstract}

Keyword: Antioxidants; Mangifera pajang; Optimisation; Phenolic content; Response surface methodology. 